\title{
Reviewing the evidence on effectiveness and cost-effectiveness of HIV prevention strategies in Thailand
}

\author{
Juntana Pattanaphesaj* and Yot Teerawattananon
}

\begin{abstract}
Background: Following universal access to antiretroviral therapy in Thailand, evidence from National AIDS Spending Assessment indicates a decreasing proportion of expenditure on prevention interventions. To prompt policymakers to revitalize HIV prevention, this study identifies a comprehensive list of HIV/AIDs preventive interventions that are likely to be effective and cost-effective in Thailand.
\end{abstract}

Methods: A systematic review of the national and international literature on HIV prevention strategies from 1997 to 2008 was undertaken. The outcomes used to consider the effectiveness of HIV prevention interventions were changes in HIV risk behaviour and HIV incidence. Economic evaluations that presented their results in terms of cost per HIV infection averted or cost per quality-adjusted life year (QALY) gained were also included. All studies were assessed against quality criteria.

Results: The findings demonstrated that school based-sex education plus life-skill programs, voluntary and routine HIV counselling and testing, male condoms, street outreach programs, needle and syringe programs, programs for the prevention of mother-to-child HIV transmission, male circumcision, screening blood products and donated organs for $H I V$, and increased alcohol tax were all effective in reducing HIV infection among target populations in a cost-effective manner.

Conclusion: We found very limited local evidence regarding the effectiveness of HIV interventions amongst specific high risk populations. This underlines the urgent need to prioritise health research resources to assess the effectiveness and cost-effectiveness of HIV interventions aimed at reducing HIV infection among high risk groups in Thailand.

\section{Background}

Since the introduction of the universal health insurance coverage policy in 2001, Thailand has sought to further ensure efficient resource allocation in the health sector [1]. Evidence-based decision making requires that decisions about health and health care are based on best available information. To use such an approach it is necessary to appraise what constitutes evidence in relation to health-enhancing interventions. While the use of effectiveness information alone to justify health care resource allocation is still common practice, decision makers, academics and health care professionals are increasingly interested in cost-effectiveness data to guide policy mak-

\footnotetext{
* Correspondence: juntana.p@hitap.net

1 Health Intervention and Technology Assessment Program (HITAP), Ministry of Public Health, Tiwanon Road, Muang, Nonthaburi, 11000, Thailand

Full list of author information is available at the end of the article
}

ing. Such evaluation are designed to guide explicit resource allocation decisions by comparing the incremental costs and consequences of alternative health care interventions [2].

Thailand is classified as facing a mixture of concentrated and generalized epidemics of HIV infection[3], similar to other countries such as South Africa, Egypt, Russia, and Papua New Guinea [4]. High HIV prevalence has been observed among some particular populations, for example, men who have sex with men, injecting drug users (IDUs), and female sex workers, while HIV prevalence among pregnant women was relatively low (0.8\%) [5]. It is noteworthy that the prioritisation of strategies for dealing with sexually transmitted infections and HIV/ AIDS was a product of their perceived high disease burden, although often without reliable evidence regarding 
the effectiveness and cost-effectiveness of the interventions themselves. Furthermore, many HIV/AIDS programs have been implemented without close monitoring, or rarely incorporated well-defined control or comparison groups necessary to identify their actual effect size. In parallel to these prevention strategies, a policy for universal antiretroviral treatment has been in operation in Thailand since 2001, with almost 150,000 individuals living with HIV/AIDS currently reaching the program. Evidence from the National AIDS Spending Assessment indicated a decreasing proportion of expenditure on prevention intervention from $18 \%$ in 2000 to $13 \%$ in 2004 [6].

Although there were some prior attempts to provide information for guiding policy decisions regarding resource allocation towards HIV prevention, these all had limitations in their applicability to the Thai health care setting. Bollinger [7] provides an extensive review of the literature assessing impacts of HIV prevention interventions in developing settings and applied a matrix of effectiveness coefficients to prioritize the interventions. His major finding is that interventions that included interpersonal contact offered a greater impact than interventions targeting a more general audience; however, the impact was measured only in terms of sexual behaviour change and did not include program costs as a prioritizated criterion. Meanwhile, Cohen et al [8] and the second edition of "Disease Control Priorities in Developing Countries" (hereafter "DCP2") [9] adopted a 'maximization concept' by using economic evaluation as the primary resource allocation criterion but neither of them was considered applicable to the Thai setting; Cohen et al provide an HIV prevention cost-effectiveness league table tailored to the US setting while DCP2 provided policy recommendations on HIV prevention across a broader range of health care settings.

This paper addresses the need to assess the usefulness and value for money of HIV/AIDS prevention interventions. It aims to make a comprehensive list of interventions that are likely to be effective and cost-effective in the Thai setting. This information can be crucial for guiding public investment to lessen both the short and longterm impacts of HIV/AIDS in Thailand by re-emphasising the role of prevention as compared with that of treatment in managing the epidemic.

\section{Methods}

\section{Scope and type of interventions}

Interventions included in this review were those that showed evidence of reducing HIV incidence or risk behaviours likely to effect horizontal and vertical HIV transmission. The set of interventions was not restricted to those used in practice in Thailand or funded by the Thai government. It also covered interventions provided at all levels, i.e. individuals, groups, and communities which are likely to be beneficial in the reduction of the HIV/AIDS epidemic worldwide.

Given that a wide range of interventions were included in this study, it is imperative that they have clear definitions and detailed information to ensure a better understanding of, for example, their precise aims, what their delivery modes are, and at whom the interventions are targeted. A lack of clarity and descriptive detail of interventions makes it difficult to assess and compare either the effectiveness or cost-effectiveness in different settings. It is also impossible to make sensible recommendations with regards to policy decision making if there are no concise definitions for commonly implemented intervention approaches.

It was necessary, therefore, for this study to establish or adopt a standard structure to define and classify interventions for the prevention of HIV/AIDS. Based on the recommendations made by UNAIDS [10], HIV prevention interventions are grouped into five broad categories as follows:

1. Interventions that affect knowledge, attitude and beliefs and influence psychological and social correlates of risk;

2. Harm reduction interventions that lower the risk of a behaviour, but do not eliminate the behaviour;

3. Biological/biomedical interventions that strive to reduce $\mathrm{HIV}$ infection and transmission risk;

4. Mitigation of barriers to prevention and negative social outcomes of HIV infection;

5. Mitigation of biological outcomes of HIV infection.

However, as the fifth category was not related to HIV prevention, it was not included in this review. From the above recommendations, we provide a definition and classification of each HIV prevention intervention in additional file 1: Table S1.

\section{Sources of information}

We obtained literature published in Thai or English from 1997 to 2008 . The studies conducted within a Thai setting were given a higher priority since they better recognise the resource and infrastructure limitations that are specific to the health care system in Thailand, as well as the effectiveness of interventions which are affected by context specific factors. The review of the Thai literature, therefore, included both published and unpublished (grey) literature such as research reports, Master's dissertations or Ph.D. theses, which are considered highly relevant to the Thai context. If local data regarding effectiveness or cost-effectiveness of an intervention were not available, then a systematic search of Pubmed and Cochrane databases was carried out. A broad search strategy with appropriate $\mathrm{MeSH}$ terms and keywords was used in combination with a filter to restrict type of studies to systematic reviews, meta-analysis, randomized 
controlled trial, case control studies or cohort studies. Search terms used included 'acquired immunodeficiency syndrome', 'HIV', 'prevention and control', 'primary prevention', 'intervention studies', or 'early intervention'. Exclusion criteria were: i) publications of the same study, ii) descriptive studies, iii) assessment of satisfaction, knowledge and attitude towards HIV/AIDS, risk behaviours and program activities (not outcomes), iv) reports of case studies, and v) cost analyses.

\section{Effectiveness of interventions}

The effectiveness of interventions can be measured in a number of ways. Figure 1 (adapted from [11]) shows the concept of outcome hierarchies that emphasize the difference between 'immediate', 'intermediate' and 'final' outcomes of HIV interventions. Immediate measures of effectiveness of HIV interventions are characterised by change in knowledge, attitude, perception and skills of the individuals. In many HIV programs, the changes were reported in terms of trust, caution and received assurances. Further along the continuum, these immediate changes can subsequently affect health behaviours and health determinants, for example, condom use, abstinence, sharing injection equipments, or fewer sexual partners. Finally, changes in incidence or morbidity or mortality should be evaluated as the final or ultimate goal of the program. The primary criterion for selection of studies was that they report the effectiveness in terms of the changes in HIV risk behaviour and HIV incidence. We deliberately excluded descriptive or qualitative reports from the review as these most often do not provide comparable measures of outcome. Studies reporting outcomes in terms of improvement in attitude or knowledge were also excluded because changes in these are not always directly associated with behavior change [12].

\section{Cost-effectiveness of interventions}

The review included economic evaluation studies that presented their results in terms of cost per HIV infection averted, or cost per quality-adjusted life year (QALY) gained, or cost per disability-adjusted life year (DALY) averted. This review compared the value for money of different HIV/AIDS preventive interventions using a societal viewpoint since it is most relevant to priority setting in health care. However, if the evaluation took the more limited health care provider perspective, this was used instead.

Differences in monetary currencies and unit costs between locations and over time are among the most commonly cited obstacles to applying economic evaluation findings across different settings. This study adjusted all cost-effectiveness ratios in a common currency, the international dollar, at their 2008 value, using national consumer price index (CPI) and purchasing power parity (PPP) information from the International Monetary Fund (IMF) [13].

With regard to the thresholds for considering an intervention to be cost-effective, the Subcommittee for development of the National List of Essential Medicines in Thailand developed its own threshold as a criterion to include or exclude medicines from the reimbursement list [14]. Interventions with a cost per QALY gained below 100,000 THB (approximating the Thai GDP per capita) are considered favourably for inclusion. Given the fact that 11.23 QALYs could be saved from one HIV infection avoided [15], the thresholds for one HIV infection averted was approximately 90,000 PPP\$.

\section{Quality assessment}

Systematic reviews and meta-analyses of high quality $\mathrm{RCTs}$ were considered the most favourable data sources

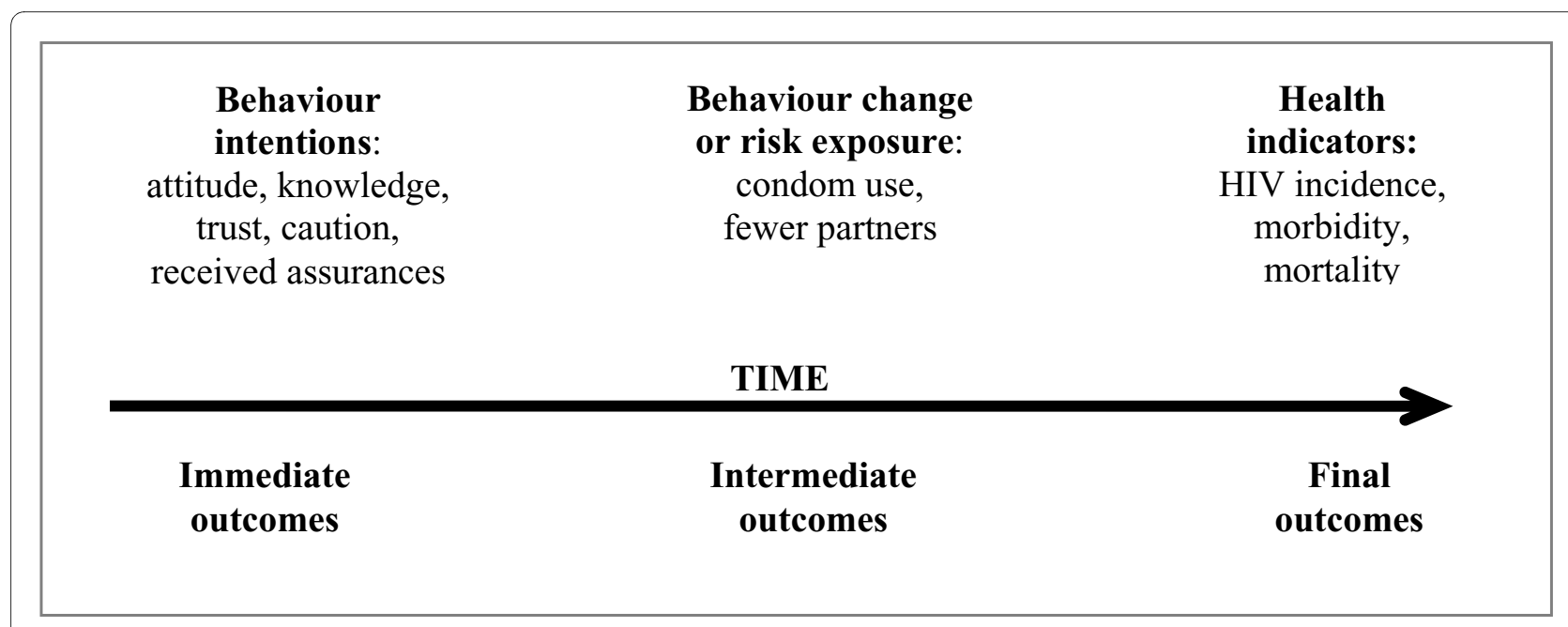

Figure 1 Outcome measures for HIV prevention interventions 
[2]. The advantages of using systematic reviews of clinical effects are twofold. First, a more precise estimate can be attained from combining the outcome data from a number of studies. Second, by using the results from studies carried out in a range of settings, assuming that these studies are sufficiently homogenous to be comparable, the estimate can then be applied to a more general patient population with different baseline risks, rather than specifically for a population group selected for an individual trial. In cases where a meta-analysis of RCT(s) was not available alternative evidence sources were used in accordance with the hierarchy shown in table 1.

\section{Results}

\section{Description of studies}

Searching the Thai databases initially identified a total of 932 abstracts (see figure 2). Of these, 890 abstracts were excluded based on our exclusion criteria. From the full text review of the remaining 42 papers, only fourteen papers were found to be relevant and included in the analysis. Of the 28 papers excluded, 25 papers reported

\section{Table 1: Levels of clinical evidence}

\begin{tabular}{ll}
\hline $\mathrm{A}+$ & Systematic reviews \& meta-analyses of RCTs or RCT(s) \\
conducted in Thailand with a very low risk of bias*.
\end{tabular}

A Systematic reviews \& meta-analyses of RCTs or RCT(s) conducted internationally with a very low risk of bias.

B+ Systematic reviews \& meta-analyses of RCTs or RCT(s) conducted in Thailand with a high risk of bias.

B Systematic reviews \& meta-analyses of RCTs or RCT(s) conducted internationally with a high risk of bias.

C+ Systematic reviews of case control or cohort studies conducted in Thailand with a very low risk of confounding, bias, or chance and a high probability that the relationship is causal.

C Systematic reviews of case control or cohort studies conducted internationally with a very low risk of confounding, bias, or chance and a high probability that the relationship is causal.

D+ Case control or cohort studies conducted in Thailand with a high risk of confounding, bias, or chance and a significant risk that the relationship is not causal.

D Case control or cohort studies conducted internationally with a high risk of confounding, bias, or chance and a significant risk that the relationship is not causal.

\footnotetext{
* A bias is a systematic error, or deviation from the truth, in results
} or inferences. only immediate outcomes of the HIV prevention programs. For example, two papers that reported the effectiveness of the distribution of condom vending machines in the communities, used only numbers of condoms sold per machine and/or customer's satisfaction as their outcome measures $[16,17]$. Three other papers that evaluated drug regimens for the prevention of vertical HIV transmission, were excluded because the regimen under investigation(AZT regimens), is no longer used in clinical practice in Thailand [18-20]. The remaining 14 studies [21-34] were included in the analysis.

We identified 1,394 abstracts from the international literature (see figure 3). After reading the abstracts, 1,203 studies were eliminated because they were editorials, descriptive, or qualitative reports. In addition, we also excluded a number of studies that assessed the effectiveness and cost-effectiveness of programs for the prevention of mother-to-child HIV transmission because relevant Thai studies had already been identified. The full text of the remaining 191 studies was reviewed and 66 studies [35-100] were considered relevant and included in the analysis in the final stage.

Additional file 2: Table S2 summarizes the effectiveness and cost-effectiveness of each HIV prevention intervention based on the reviews of domestic and international studies. It was not surprising that a much larger proportion of effectiveness and cost-effectiveness studies were conducted in international settings, mainly the US and Sub-Saharan Africa. In both the Thai and the international settings there were more effectiveness studies than cost-effectiveness ones (11 and 48 effectiveness studies in the Thai and international settings, respectively, versus 3 and 18 cost-effectiveness studies in each of the respective settings).

Most of the assessments focused on interventions affecting knowledge, attitudes and beliefs (36/63 or 57\%), followed by biological/biomedical interventions $(16 / 63$ or $25 \%)$, harm reduction interventions $(9 / 63$ or $15 \%)$ and, lastly, mitigation of barriers to prevention and negative social outcomes of HIV infection (2/63 or 3\%).

\section{Effectiveness and cost-effectiveness of HIV prevention intervention}

The findings demonstrated that male condoms use, street outreach programs, programs for the prevention of mother-to-child HIV transmission, circumcision, and needle and syringe programs were the only interventions to show strong evidence of reducing HIV infection among target populations.

Figure 4 compares the cost per HIV infection averted of each HIV prevention intervention. It can be seen that the cost-effectiveness ratios vary largely, ranging from 70 PPP\$ per HIV infection averted for screening blood product to 2,000,000 PPP\$ per HIV infection averted for 


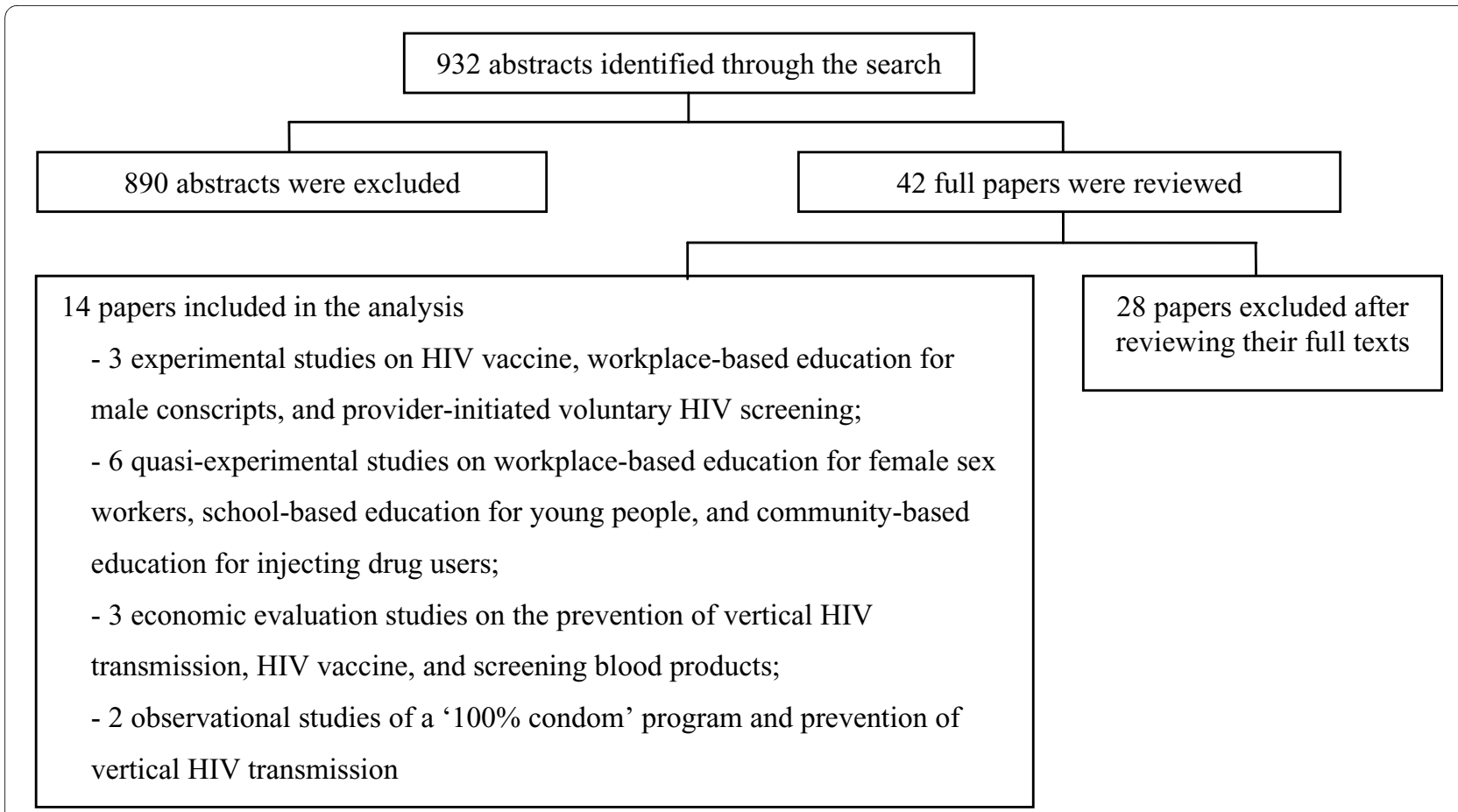

Figure $\mathbf{2}$ Literature review profile of the Thai literature

community-based education for low income women. It is likely that biological/biomedical interventions (highlighted in blue) are more cost-effective than those interventions affecting knowledge, attitudes and beliefs (highlighted in pink).

Figure 5 presents the modification of the figure 4 according to levels of HIV prevalence in settings where economic evaluations were conducted. It indicates that interventions performing in high HIV prevalence settings (e.g. screening blood products and donated organ for HIV or school-based sex education program in settings with high HIV epidemic) are likely to be cost-effective whereas interventions performing in low HIV prevalence settings (e.g. school-based sex education program in settings with low HIV prevalence or community-based education for low income women) are less likely to be costeffective.

Figure 6 summarises the findings from the review and prioritises HIV prevention interventions based on effectiveness and cost-effectiveness evidence. The table presents results by targeted population including female sex workers, IDUs, men who have sex with men and serodiscordant couples, who are currently the major sources of HIV infection in Thailand.

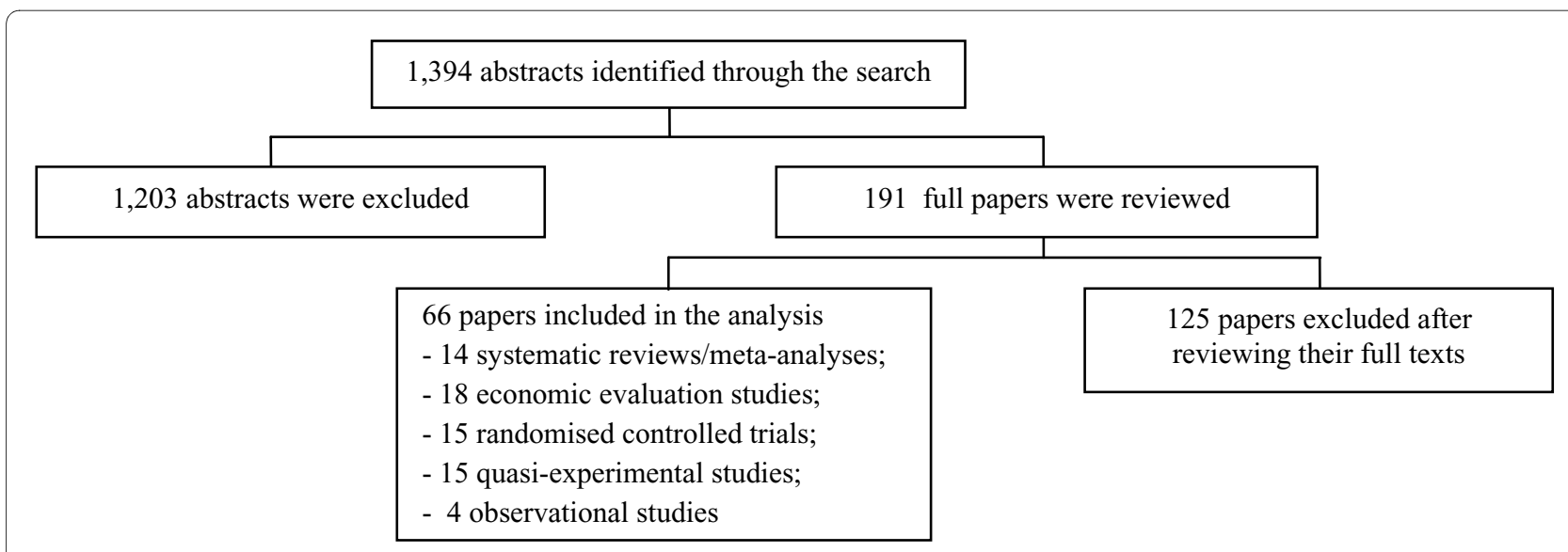

Figure 3 Literature review profile of the international literature. 


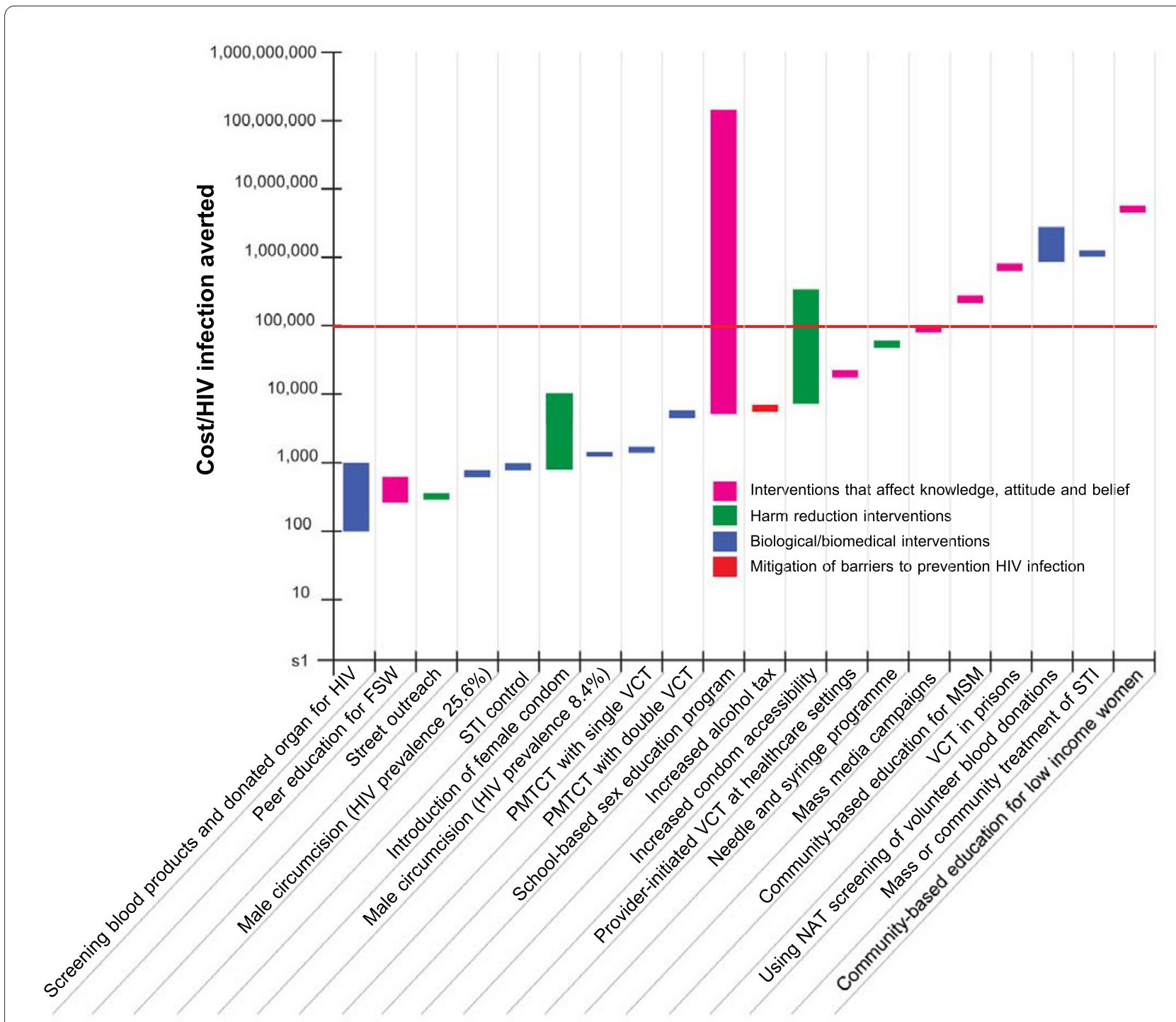

Figure 4 Summary of cost-effectiveness data for HIV prevention intervention by type of interventions (PPP\$ 2008 per HIV infection averted).

Those interventions proven to be both effective and cost-effective for female sex workers were: voluntary HIV counselling and testing, peer education, and male and female condom use. Community-based education and workplace-based education proved to be effective, but no evidence regarding the value for money among female sex workers was found. Although the use of microbicides is still in the trial phase, the evidence so far suggests that microbicides and sexually transmitted infections (STI) control were not effective in preventing HIV transmission amongst female sex workers.

Condom use was proven to be the only effective and cost-effective intervention for men who have sex with men while voluntary HIV counselling and testing demonstrated effectiveness but lacked cost-effectiveness infor- mation. Community-based education was clinically effective but cost-ineffective. Peer education and STI control were shown to be ineffective amongst this population.

For injecting drug users, voluntary HIV counselling and testing, condom use, needle and syringe programs, and street outreach were amongst the programs shown to be both effective and cost-effective. Needle social marketing, peer education, and substitution treatment demonstrated clinical effectiveness but were unsupported by economic evidence. Community-based education, HIV vaccines, STI control and post-exposure prophylaxis were shown to be ineffective in the prevention of HIV transmission amongst IDUs. 


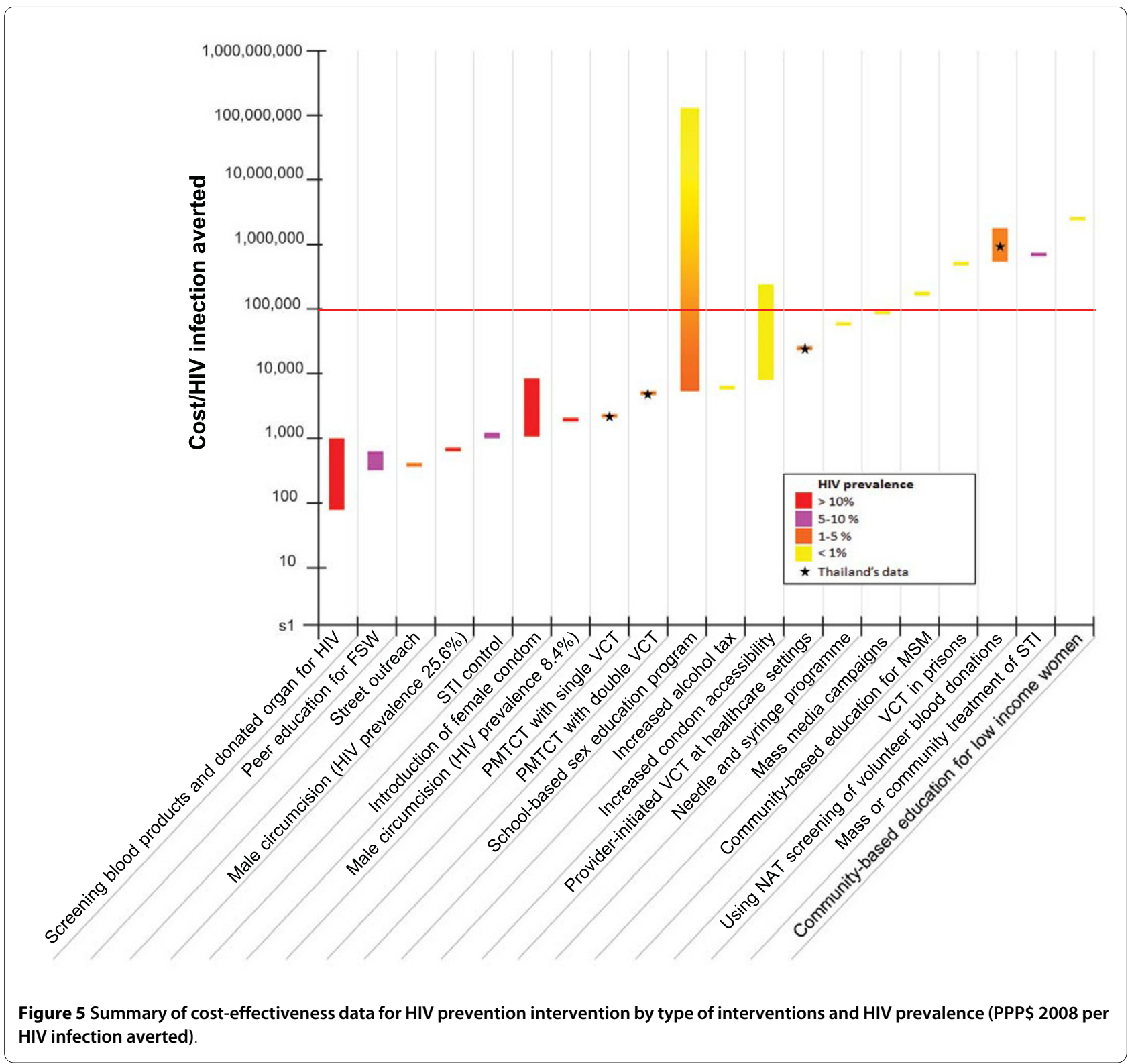

Condom use was the only interventions proven to be both effective and cost-effective for serodiscordant couples. Voluntary HIV counselling and testing was proven to be clinically effective but no cost-effectiveness information was available. STI control was not effective in preventing HIV transmission amongst this population.

With respect to information availability, voluntary HIV counselling and testing and condom use were the only interventions with extensive evaluations concerning effectiveness and cost-effectiveness across the different population groups. The main identified information gaps were for the following interventions: routine (providerinitiated) voluntary HIV screening at healthcare settings, introduction of female condoms, HIV vaccine, male circumcision, microbicides, and post-exposure prophylaxis.
The evidence was particularly scarce for some of the targeted populations, namely serodiscordant couples, prison inmates and health care workers.

\section{Discussion}

This review demonstrated several barriers to the use of effectiveness and cost-effectiveness evidence for policy decision making or program reorientation regarding HIV/AIDS. First, a lack of proper assessment about the effectiveness and/or cost-effectiveness outcomes of many interventions poses a significant challenge in making evidence-based health policy decisions. We found that most domestic studies evaluated the effectiveness or costeffectiveness of interventions using only immediate measures such as knowledge, attitudes, perception, and skills. 


\begin{tabular}{|c|c|c|c|c|c|c|c|c|c|}
\hline Interventions & FSW & MSM & IDU & SDC & Preg & PI & HCW & Young & G pop \\
\hline \multicolumn{10}{|c|}{$\begin{array}{l}\text { I. Interventions that affect knowledge, attitude and beliefs and influence psychological and social } \\
\text { correlates of risk }\end{array}$} \\
\hline \multicolumn{10}{|c|}{\begin{tabular}{|l|l|l|l|l} 
Abstinence-only programs & & & \\
\end{tabular}} \\
\hline \multicolumn{10}{|l|}{ Abstinence-plus programs } \\
\hline \multicolumn{10}{|l|}{ Community-based education } \\
\hline \multicolumn{10}{|l|}{ Mass media campaigns } \\
\hline \multicolumn{10}{|l|}{ Peer education } \\
\hline \multicolumn{10}{|l|}{$\begin{array}{l}\text { Routine (provider-initiated) voluntary HIV } \\
\text { screening at healthcare settings }\end{array}$} \\
\hline \multicolumn{10}{|l|}{$\begin{array}{l}\text { School-based sex education programs } \\
(+ \text { life skills) }\end{array}$} \\
\hline \multicolumn{10}{|l|}{$\begin{array}{l}\text { Voluntary HIV counselling and testing (VCT) } \\
( \pm \text { STI clinic and condom distribution) }\end{array}$} \\
\hline \multicolumn{10}{|c|}{$\begin{array}{l}\text { Workplace-based education } \\
( \pm \text { condom distribution / free STI clinic) }\end{array}$} \\
\hline \multicolumn{10}{|c|}{ II. Harm reduction interventions that lower the risk of a behaviour, but do not eliminate the behaviour } \\
\hline \multicolumn{10}{|c|}{\begin{tabular}{|l|l|l|l|l|l|l|l|}
$\begin{array}{l}\text { Condom use } \\
\text { (availability and accessibility) }\end{array}$ & & & & & & & \\
\end{tabular}} \\
\hline \multicolumn{10}{|l|}{ Introduction of female condoms } \\
\hline \multicolumn{10}{|l|}{ Needle and syringe program } \\
\hline \multicolumn{10}{|l|}{ Needle social marketing } \\
\hline \multicolumn{10}{|l|}{ Street outreach } \\
\hline \multicolumn{10}{|c|}{ III. Biological/biomedical interventions that strive to reduce HIV infection and transmission risk } \\
\hline \multicolumn{10}{|c|}{\begin{tabular}{l|l|l|l|l|l|l|l} 
HIV vaccine & & & & & & &
\end{tabular}} \\
\hline \multicolumn{10}{|l|}{ STI control } \\
\hline \multicolumn{10}{|l|}{$\begin{array}{l}\text { Mass or community treatment of sexually } \\
\text { transmitted infections }\end{array}$} \\
\hline \multicolumn{10}{|l|}{ Male circumcision } \\
\hline \multicolumn{10}{|l|}{ Microbicides } \\
\hline \multicolumn{10}{|l|}{ Post-exposure prophylaxis } \\
\hline \multicolumn{10}{|l|}{$\begin{array}{l}\text { Prevention of mother-to-child } \\
\text { transmission of HIV }\end{array}$} \\
\hline \multicolumn{10}{|l|}{$\begin{array}{l}\text { Screening blood products and donated } \\
\text { organs for HIV }\end{array}$} \\
\hline \multicolumn{10}{|l|}{ Substitution treatment } \\
\hline \multicolumn{10}{|c|}{ 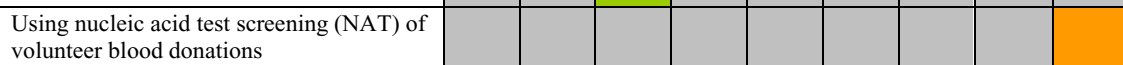 } \\
\hline \multicolumn{10}{|c|}{ IV. Mitigation of barriers to prevention and negative social outcomes of HIV infection } \\
\hline Increased alcohol tax & & & & & & & & & \\
\hline Microfinance & & & & & & & & & \\
\hline $\begin{array}{l}\text { Microfinance } \\
\text { (combined with education) }\end{array}$ & & & & & & & & & \\
\hline
\end{tabular}

The colour of effectiveness and cost-effectiveness

\begin{tabular}{lccl}
\hline Colours & Effectiveness & $\begin{array}{c}\text { Cost- } \\
\text { effectiveness }\end{array}$ & \multicolumn{1}{c}{ Description } \\
\hline dark green & Yes & Yes & The intervention proven to be effective and cost-effective \\
\hline light green & Yes & $\begin{array}{c}\text { Data not } \\
\text { available }\end{array}$ & $\begin{array}{l}\text { The intervention proven to be effective but no evidence regarding cost- } \\
\text { effectiveness }\end{array}$ \\
\hline orange & Yes & No & The intervention proven to be effective but not cost-effective \\
\hline red & No & $\begin{array}{c}\text { No, data not } \\
\text { available }\end{array}$ & The intervention proven to be neither effective nor cost-effective \\
\hline white & $\begin{array}{c}\text { Data not } \\
\text { available }\end{array}$ & $\begin{array}{c}\text { Data not } \\
\text { available }\end{array}$ & $\begin{array}{l}\text { No evidence concerning effectiveness or cost-effectiveness of the } \\
\text { intervention }\end{array}$ \\
\hline grey & & & The intervention is not relevant or used for particular target population \\
\hline
\end{tabular}

Figure 6 Summary of findings by intervention and targeted population. Abbreviations FSW - female sex worker; MSM - men who have sex with men; IDU - injecting drug user; SDC - serodiscordant couples; Preg - pregnant women; PI - prison inmate; HCW - healthcare worker; Young - people aged 10-24 years old; G pop - general people. 
The use of such immediate measures severely limits the usefulness of the evaluations because they do not allow for the comparison of value for money across different types of interventions, due to variation in outcome measurement. In addition, these immediate outcomes may not be of primary interest to decision makers or health care planners when they consider health resource allocation.

Second, although high quality evidence was available for assessing many of the interventions' effectiveness, a major concern is the strength of evidence used to generate cost-effectiveness information. For example, many cost-effectiveness studies obtained the their effectiveness data from more bias-prone sources, such as expert opinion; in the case of the economic evaluation of HIV vaccine particularly unconvincing assumptions were applied [99]. This problem is also found in the economic appraisals of STI control and mass media campaigns which showed inconclusive clinical effects but good value for money $[98,100]$. Economic evaluation can be useful for guiding policy decisions only when it is performed correctly and reported accurately; these findings clearly depict barriers that would diminish the use of cost-effectiveness evidence to inform policy decisions.

Third, despite the emphasis we placed on finding local information on HIV prevention, the majority of studies identified in our reviews originate in other settings. Although their transferability/generalizability to the Thai settings might be questionable, it remains necessary to rely on these to inform policy making. In addition, most studies reporting the effectiveness and cost-effectiveness of HIV interventions were identified from international publications rather than domestic journals or grey literature (see table 2). This reflects the fact that good quality studies conducted both in Thailand or elsewhere are likely to be published in international journals. Thus, it is sensible to recommend that the international databases are still major sources of information, and can be used to inform decision making about the effectiveness and costeffectiveness of HIV prevention interventions.
The findings in this study are mostly consistent with the international literature, and notably the DCP2 findings [9]; male condoms, street outreach programs, programs for the prevention of mother-to-child HIV transmission, and circumcision were the only interventions to show strong evidence of reducing HIV infection among target populations. The DCP2 also identified these interventions, with the exception of circumcision, in its recommendations for concentrated epidemic areas including East Asia and the Pacific region. The differences between the recommendations from DCP2 and our findings are as follows:

- Although it was recommended in DCP2, there was a lack of strong evidence to indicate that community-based education offers good value for money in the prevention of HIV infection in either low or high HIV prevalence settings.

- In our review there were very consistent results showing that screening blood products and donated organs for $\mathrm{HIV}$ is very cost-effective while there was little reference to this intervention in the DCP2.

- This study found that interventions that aim to mitigate barriers to prevention and negative social outcomes of HIV infection such as increased alcohol tax and microfinancing also held promise of being effective. These interventions should be assessed in the future.

The differences between the DCP2 report and this study may be explained by the fact that DCP2 did not employ a comprehensive and systematic search for evidence, resulting in a number of published and unpublished studies being excluded. Furthermore, this study gave a higher priority for evidence from Thai context at which the recommendations are primarily aimed, while the DCP2 report aims to provide policy recommendations across a broader range of health care settings.

It is interesting to note that we found very limited local information about HIV interventions amongst specific high risk populations (i.e. IDUs, men who have sex with men, female sex workers, and young people). Of the nine interventions conducted in Thailand identified in our

\section{Table 2: Review profile of domestic literature}

\begin{tabular}{lccc}
\hline Type of literature & Initial search & Review of full text & Final inclusion \\
\hline Articles published in domestic journals & 528 & 16 & 1 \\
Articles published in international journals & 111 & 11 & 5 \\
Theses/dissertations & 99 & 3 & 5 \\
Research reports & 24 & 1 & 2 \\
Conference proceedings & 170 & & 1 \\
& & $\mathbf{4 2}$ & $\mathbf{1 4}$ \\
\hline
\end{tabular}


review, only one study focused on a high risk group, assessing an HIV vaccine for injecting drug users. These findings underline the urgent need to prioritize health research resources to assess the effectiveness and costeffectiveness of HIV interventions aimed at the reduction of HIV infection among high risk groups.

Caution should be exercised when comparing the effectiveness and cost-effectiveness data in this study to inform policy decision making. Firstly, because many studies were conducted in various settings with different sized target populations, different HIV prevalence, different attitudes towards HIV/AIDS, and varying socio-economic and cultural determinants of behavioral responses to interventions; these factors would greatly affect not only the effectiveness of the intervention but also its value for money.

Secondly, although we have made explicit criteria to judge whether the effectiveness studies/data are good enough to be used in decision making, there was no such standard to measure the quality of cost-effectiveness studies. We found that most of the effectiveness studies are of good quality (mainly in the 1st or 2nd hierarchy) but we are in doubt of the quality of data used in many of the cost-effectiveness studies.

Lastly, it is important to recognize that effectiveness and cost-effectiveness are not the only criteria in guiding health care rationing and that political and ethical dimensions and other societal values such as equity can also play significant roles in decision making processes. However, these issues were not under consideration in this study.

\section{Conclusion}

This study found that school based-sex education plus life-skill programs, voluntary and routine HIV counselling and testing, male condoms, street outreach programs, needle and syringe programs, programs for the prevention of mother-to-child HIV transmission, male circumcision, screening blood products and donated organs for HIV, and increased alcohol tax showed strong evidence and value for money in reducing HIV infection among target populations.

We found very limited local evidence regarding the effectiveness of HIV interventions among high risk populations in Thailand. This underlines the urgent need to prioritise health research resources to assess the effectiveness and cost-effectiveness of HIV interventions aimed at reducing HIV infection among high risk groups.

This review also demonstrated several limitations in using effectiveness and cost-effectiveness evidence for policy decision making concerning HIV/AIDS. First, a lack of proper assessment about the effectiveness and/or cost-effectiveness outcomes of many interventions poses a significant challenge in making evidence-based health policy decisions and program reorientation. Second, although good quality evidence was available for assessing intervention effectiveness, a major concern is the strength of evidence used to generate the cost-effectiveness information. Third, although we put more effort into identifying local information on HIV prevention, a majority of the studies included in the final analysis were identified from international databases rather than local sources, and may not be entirely applicable in the Thai context.

\section{Additional material}

Additional file 1 Table S1 Classification and definition of HIV prevention interventions in the review. The table describing the classification and definition of HIV prevention interventions in the review (11 pages). Additional file 2 Table S2 Summary concerning the effectiveness and cost-effectiveness evidence of HIV prevention interventions. The table describing the effectiveness and cost-effectiveness evidence of HIV prevention interventions (30 pages).

Competing interests

The authors declare that they have no competing interests.

\section{Authors' contributions}

All named authors contributed jointly to the conception, data collection, analysis, and writing of the report. All authors read and approved the final manuscript.

\section{Acknowledgements}

This study was conducted with funding from the World Bank. The Health Intervention and Technology Assessment Program (HITAP) was supported by the Thai Health Promotion Foundation, the Health Systems Research Institute, and the Bureau of Policy and Strategy Ministry of Public Health. The findings and opinions in this report have not been endorsed by the above funding agencies and do not reflect the policy stance of these organizations. Special thanks also to Ms.Chanida Leartpitakpong and Mr.Teera Sirisamutr for their kindness and facilitation of the data collection. The authors are also grateful to many individuals and organizations, from whom we have obtained valuable data and information for use in our report. We would like to express our gratitude to the experts, especially John Stover and Susan May Cleary, who provided helpful comments and suggestions on the research proposal and early versions of preliminary report.

\section{Author Details}

Health Intervention and Technology Assessment Program (HITAP), Ministry of Public Health, Tiwanon Road, Muang, Nonthaburi, 11000, Thailand

Received: 7 July 2009 Accepted: 7 July 2010

Published: 7 July 2010

\section{References}

1. Tangcharoensathien $\mathrm{V}$, Tantivess $\mathrm{S}$, Teerawattananon $\mathrm{Y}$, Auamkul N, Jongudoumsuk P: Universal coverage and its impact on reproductive health services in Thailand. Reprod Health Matters 2002, 10:59-69.

2. Teerawattananon $Y$, Russell S, Mugford M: A systematic review of economic evaluation literature in Thailand: are the data good enough to be used by policy-makers? Pharmacoeconomics 2007, 25:467-479.

3. Bureau of Epidemiology: Results of national Sero Sentinel for HIV prevalence, various rounds. Nonthaburi: Ministry of Public Health; 2007.

4. Wilson D, Halperin DT: Know your epidemic, know your response: a useful approach, if we get it right. Lancet 2008, 372:423-426.

5. National AIDS Prevention and Alleviation Committee: UNGASS Country progress report: Thailand. Ministry of Public Health; 2008.

6. Tangcharoensathien V, Chokchaicharn H, Tisayaticom K, Teokul W, Patcharanarumol W: Asia pacific regional report on national AIDS 
spending assessment 2000-2004. Nonthaburi: International Health Policy Program, Ministry of Public Health; 2006.

7. Bollinger LA: How can we calculate the 'E' in 'CEA'? Aids 2008, 22(Suppl 1):S51-57.

8. Cohen DA, Wu SY, Farley TA: Cost-effective allocation of government funds to prevent HIV infection. Health Aff (Millwood) 2005, 24:915-926.

9. Jamison DT, Breman JG, Measham AR, Alleyne G, Claeson M, Evan DB, Jha P, Mills A, Musgrove P: Disease control priorities in developing countries Edited by: 2. New York: Oxford University Press; 2006.

10. Sweat M: A framework for classifying HIV prevention interventions USA: Joint United Nations Programme on HIV/AIDS (UNAIDS); 2008.

11. Thorogood M, Coombes Y: Evaluating health promotion: practice and methods New York: Oxford University Press Inc; 2006.

12. Chaisoontorn O: Meta-analysis of research on knowledge attitude and behaviors regarding HIV prevention in the upper Northern region. In Master's Degree Chiang Mai University, Department of Education; 1999.

13. World Economic and Financial Surveys: World Economic Outlook Database [http://imforg/external/pubs/ft/weo/2009/01/weodata/ index.aspx]

14. The Subcommittee for Development of the National List of Essential Medicines: The threshold at which an intervention becomes costeffective. Meeting of the Subcommittee for Development of the National List of Essential Medicine 9/2550 20th December 2007; Jainad Narendhorn meeting room, Food and Drug Administration 2007.

15. Holtgrave DR, Pinkerton SD: Updates of cost of illness and quality of life estimates for use in economic evaluations of HIV prevention programs. J Acquir Immune Defic Syndr Hum Retrovirol 1997, 16:54-62.

16. Kaeodumkoeng N, Lertpiriyasuwat C, Chawanangkul V, Sukhonthaman C, Jantharathaneewat K, Chanthongkum N, Thanprasertsuk S: Model Development of Condom Accessibility by Condom Vending Machine. Thai Aids J 2007, 19:73-84.

17. Umsuriya S, Srisawang O, Pibaljommee T, Unnanan M, Netthip N: Evaluation of condom use accession by condom teller machine, Ayutthaya province 2006. Disease Control Journal 2006, 10:103-108.

18. Kongsin S, Kongsin P, Jiamton S, Intraprasong B, Boonthum A, Tarunothai U, Chumthong P: Pilot Study Potential Benefit of AZT Preventive Therapy in Perinatal HIV Transmission and Its Cost-effectiveness Analysis: A Case Study of BMA Medical College and Vajira Hospital. Bangkok 2004.

19. Kanshana S, Thewanda D, Teeraratkul A, Limpakarnjanarat K Amornwichet P, Kullerk N, Akksilp S, Sereesittipitak V, Mastro TD, Simonds $\mathrm{RJ}$ : Implementing short-course zidovudine to reduce mother-infant HIV transmission in a large pilot program in Thailand. Aids 2000, 14:1617-1623

20. Chantanakorn N, Weerawongphom R: The Prevention of Mother-toChild Transmission Project (PMTCT) of Phichit Province FY 2001-2004. Thai Aids J 2006, 18:214-225.

21. Celentano DD, Bond KC, Lyles CM, Eiumtrakul S, Go VF, Beyrer C, na Chiangmai C, Nelson KE, Khamboonruang C, Vaddhanaphuti C: Preventive intervention to reduce sexually transmitted infections: a field trial in the Royal Thai Army. Arch Intern Med 2000, 160:535-540.

22. Celentano DD, Nelson KE, Lyles CM, Beyrer C, Eiumtrakul S, Go VF, Kuntolbutra S, Khamboonruang C: Decreasing incidence of HIV and sexually transmitted diseases in young Thai men: evidence for success of the HIV/AIDS control and prevention program. Aids 1998, 12:F29-36.

23. Lallemant M, Jourdain G, Le Coeur S, Mary JY, Ngo-Giang-Huong N, Koetsawang S, Kanshana S, McIntosh K, Thaineua V: Single-dose perinatal nevirapine plus standard zidovudine to prevent mother-tochild transmission of HIV-1 in Thailand. N Eng/ J Med 2004, 351:217-228.

24. Lertiendumrong J, Techakehakij W, Pongpirul K, Tangcharoensathien V, Srirattana S: Using nucleic acid testing in screening donated blood in Thailand: a policy analysis. Nonthaburi: International Health Policy Program; 2007.

25. NaThalang D: The effectiveness of a health education program on AIDS prevention through behavior modification among traditional massage working girls in Satun province. In Master of Science Mahidol University, Faculty of Public Health; 2001.

26. Nilabut S: Achievement of integrated teaching using the applied protection motivation theory on AIDS prevention among informal education students in Saraburi. In Master of Science Mahidol University, Faculty of Public Health; 1999.
27. Nobnorb S: The effectiveness of health education program on AIDS prevention among vocational male students in Krabi province. In Master of Science Mahidol University, Faculty of Public Health; 2002.

28. Pitisuttithum P, Gilbert P, Gurwith M, Heyward W, Martin M, van Griensven F, Hu D, Tappero JW, Choopanya K: Randomized, double-blind, placebocontrolled efficacy trial of a bivalent recombinant glycoprotein 120 HIV-1 vaccine among injection drug users in Bangkok, Thailand. Infect Dis 2006, 194:1661-1671.

29. Simtaraj P: Effects of skills development for prevention of sexual risk behavior on perceived self-efficacy and sexual risk behavior among male vocational students. In Master degree of Nursing Chiang Mai University, Department of Medical and Surgical Nursing; 2001.

30. Sunsiri M: An application of life skills to AIDS prevention among grade 9 junior high school students in Burirum province. In Master of Science (Public Health) Mahidol University, Faculty of Public Health; 2002.

31. Teerawattananon Y, Hiransuthikul N, Hanvoravongchai P, Tantivess S, Lertpiriyasuwat C, Chaikledkaew U, Thavorncharoensap M, Youngkong S, Leelukkanaveera Y, Mohara A, et al.: Effectiveness of routine offer of HIV counseling and testing at community hospitals in Thailand. Nonthaburi: Health Intervention and Technology Assessment Program; 2008.

32. Teerawattananon Y, Vos T, Tangcharoensathien V, Mugford M: Costeffectiveness of models for prevention of vertical HIV transmission voluntary counseling and testing and choices of drug regimen. Cost Eff Resour Alloc 2005, 3:7.

33. Wongjak T, Wibulnuttakul K, Wichacharn M, Tejafong k, Cheewawat W, Saokaew P, Taecharoenkun S: A study of behavior post intervention on reducin HIV risk in intravenous drug users in Northern drug dependence treatment center and community clinic Chiangmai. Chiang Mai: Research Institute for Health Sciences, Chiang Mai University; 2004

34. Yotruean K: Using acitivities to promote self-prevention of HIV infection female sex workers, Chiang Mai Province. In Master degree of Education (Health Promotion) Chiang Mai University; 2006.

35. Jemmott JB, Jemmott LS, Braverman PK, Fong GT: HIV/STD risk reduction interventions for African American and Latino adolescent girls at an adolescent medicine clinic: a randomized controlled trial. Arch Pediatr Adolesc Med 2005, 159:440-449.

36. Jewkes R, Nduna M, Levin J, Jama N, Dunkle K, Khuzwayo N, Koss M, Puren A, Wood K, Duvvury N: A cluster randomized-controlled trial to determine the effectiveness of Stepping Stones in preventing HIV infections and promoting safer sexual behaviour amongst youth in the rural Eastern Cape, South Africa: trial design, methods and baseline findings. Trop Med Int Health 2006, 11:3-16.

37. Di Noia J, Schinke SP: Gender-specific HIV prevention with urban earlyadolescent girls: outcomes of the Keepin' It Safe Program. AIDS EduC Prev 2007, 19:479-488

38. Underhill K, Montgomery P, Operario D: Abstinence-plus programs for HIV infection prevention in high-income countries. Cochrane Database Syst Rev 2008:CD007006.

39. Underhill $K$, Operario D, Montgomery P: Abstinence-only programs for HIV infection prevention in high-income countries. Cochrane Database Syst Rev 2007:CD005421.

40. Morrison-Beedy D, Carey MP, Kowalski J, Tu X: Group-based HIV risk reduction intervention for adolescent girls: evidence of feasibility and efficacy. Res Nurs Health 2005, 28:3-15.

41. Johnson WD, Hedges LV, Ramirez G, Semaan S, Norman LR, Sogolow E, Sweat MD, Diaz RM: HIV prevention research for men who have sex with men: a systematic review and meta-analysis. J Acquir Immune Defic Syndr 2002, 30(Suppl 1):S118-129.

42. Johnson-Masotti AP, Pinkerton SD, Sikkema KJ, Kelly JA, Wagstaff DA Cost-Effectiveness of a Community-Level HIV Risk Reduction Intervention for Women Living in Low-Income Housing Developments. J Prim Prev 2005, 26:345-362.

43. Peragallo N, Deforge B, O'Campo P, Lee SM, Kim YJ, Cianelli R, Ferrer L: A randomized clinical trial of an HIV-risk-reduction intervention among low-income Latina women. Nurs Res 2005, 54:108-118.

44. Shahmanesh M, Patel V, Mabey D, Cowan F: Effectiveness of interventions for the prevention of HIV and other sexually transmitted infections in female sex workers in resource poor setting: a systematic review. Trop Med Int Health 2008, 13:659-679. 
45. Cochen DA, Wu SY, Farley TA: Structural Interventions to Prevent HIV/ Sexually Transmitted Disease: Are They Cost-Effective for Women in the Southern United States? Sex Transm Dis 2006, 33:S46-49.

46. Herbst JH, Beeker C, Mathew A, McNally T, Passin WF, Kay LS, Crepaz N, Lyles CM, Briss P, Chattopadhyay S, Johnson RL: The effectiveness of individual-, group-, and community-level HIV behavioral risk-reduction interventions for adult men who have sex with men: a systematic review. Am J Prev Med 2007, 32:S38-67.

47. Pinkerton SD, Holtgrave DR, DiFranceisco WJ, Stevenson LY, Kelly JA: CostEffectiveness of a Community-Level HIV Risk Reduction Intervention. Am J Public Health 1998, 88:1239-1242.

48. Borgia P, Marinacci C, Schifano P, Perucci CA: Is peer education the best approach for HIV prevention in schools? Findings from a randomized controlled trial. JAdolesc Health 2005, 36:508-516.

49. Creese A, Floyd K, Alban A, Guinness L: Cost-effectiveness of HIV/AIDS interventions in Africa: a systematic review of the evidence. Lancet 2002, 359:1635-1642.

50. Elford J, Bolding G, Sherr L: Peer education has no significant impact on HIV risk behaviours among gay men in London. Aids 2001, 15:535-538.

51. Flowers P, Hart GJ, Williamson LM, Frankis JS, Der GJ: Does bar-based, peer-led sexual health promotion have a community-level effect amongst gay men in Scotland? Int J STD AIDS 2002, 13:102-108.

52. Fung IC-H, Guinness L, Vickerman P, Watts C, Vannela G, Vadhvana J, Foss AM, Malodia L, Gandhi M, Jani G: Modelling the impact and costeffectiveness of the HIV intervention programme amongst commercial sex workers in Ahmedabad, Gujarat, India. BMC Public Health 2007, 7:195.

53. Garfein RS, Golub ET, Greenberg AE, Hagan H, Hanson DL, Hudson SM, Kapadia F, Latka MH, Ouellet LJ, Purcell DW, et al:: A peer-education intervention to reduce injection risk behaviors for HIV and hepatitis $C$ virus infection in young injection drug users. Aids 2007, 21:1923-1932.

54. Luchters S, Chersich MF, Rinyiru A, Barasa MS, King'ola N, Mandaliya K, Bosire W, Wambugu S, Mwarogo P, Temmerman M: Impact of five years of peer-mediated interventions on sexual behavior and sexually transmitted infections among female sex workers in Mombasa, Kenya. BMC Public Health 2008, 8:143.

55. Mahat G, Scoloveno MA, De Leon T, Frenkel J: Preliminary evidence of an adolescent HIV/AIDS peer education program. J Pediatr Nurs 2008, 23:358-363

56. Miller AN, Mutungi M, Facchini E, Barasa B, Ondieki W, Warria C: An outcome assessment of an ABC-based HIV peer education intervention among Kenyan university students. J Health Commun 2008, 13:345-356.

57. Weeks MR, Li J, Dickson-Gomez J, Convey M, Martinez M, Radda K, Clair S: Outcomes of a peer HIV prevention program with injection drug and crack users: the Risk Avoidance Partnership. Subst Use Misuse 2009, 44:253-281.

58. Williamson LM, Hart GJ, Flowers P, Frankis JS, Der GJ: The Gay Men's Task Force: the impact of peer education on the sexual health behaviour of homosexual men in Glasgow. Sex Transm Infect 2001, 77:427-432.

59. Cohen DA, Wu SY, Farley TA: Comparing the cost-effectiveness of HIV prevention interventions. J Acquir Immune Defic Syndr 2004, 37:1404-1414

60. Silva M: The effectiveness of school-based sex education programs in the promotion of abstinent behavior: a meta-analysis. Health Educ Res 2002, 17:471-481.

61. Walker D: Cost and cost-effectiveness of HIV/AIDS prevention strategies in developing countries: is there an evidence base? Health Policy Plan 2003, 18:4-17.

62. Walker D, Gutierrez JP, Torres P, Bertozzi SM: HIV prevention in Mexican schools: prospective randomised evaluation of intervention. Bmj 2006, 332:1189-1194.

63. Wang LY, Davis M, Robin L, Collins J, Coyle K, Baumler E: Economic Evaluation of Safer Choices. Arch Pediatr Adolesc Med 2000, 154:1017-1024

64. Allen S, Meinzen-Derr J, Kautzman M, Zulu I, Trask S, Fideli U, Musonda R, Kasolo F, Gao F, Haworth A: Sexual behavior of HIV discordant couples after HIV counseling and testing. Aids 2003, 17:733-740

65. Bedimo AL, Pinkerton SD, Cohen DA, Gray B, Farley TA: Condom distribution: a cost-utility analysis. Int J STD AIDS 2002, 13:384-392

66. Chesson HW, Greenberg JB, Hennessy M: The cost-effectiveness of the WINGS intervention: a program to prevent HIV and sexually transmitted diseases among high-risk urban women. BMC Infect Dis 2002, 2:24.

67. Corbett EL, Makamure B, Cheung YB, Dauya E, Matambo R, Bandason T, Munyati SS, Mason PR, Butterworth AE, Hayes RJ: HIV incidence during a cluster-randomized trial of two strategies providing voluntary counselling and testing at the workplace, Zimbabwe. Aids 2007, 21:483-489.

68. Ford K, Wirawan DN, Reed BD, Muliawan P, Wolfe R: The Bali STD/AIDS Study: evaluation of an intervention for sex workers. Sex Transm Dis 2002, 29:50-58,

69. Rou K, Wu Z, Sullivan SG, Li F, Guan J, Xu C, Liu W, Liu D, Yin Y: A five-city trial of a behavioural intervention to reduce sexually transmitted disease/HIV risk among sex workers in China. Aids 2007, 21(Suppl 8):S95-101.

70. Varghese B, Peterman TA: Cost-effectiveness of HIV counseling and testing in US prisons. J Urban Health 2001, 78:304-312.

71. Weller S, Davis $\mathrm{K}$ : Condom effectiveness in reducing heterosexual HIV transmission. Cochrane Database Syst Rev 2002:CD003255.

72. Wu Z, Rou K, Jia M, Duan S, Sullivan SG: The first community-based sexually transmitted disease/HIV intervention trial for female sex workers in China. Aids 2007, 21 (Suppl 8):S89-94.

73. Coyle SL, Needle RH, Normand J: Outreach-based HIV prevention for injecting drug users: a review of published outcome data. Public Health Rep 1998, 113(Suppl 1):19-30.

74. Des Jarlais DC, Kling R, Hammett TM, Ngu D, Liu W, Chen Y, Binh KT, Friedmann P: Reducing HIV infection among new injecting drug users in the China-Vietnam Cross Border Project. Aids 2007, 21(Suppl 8):S109-114.

75. Lau JT, Zhang L, Zhang Y, Wang N, Lau M, Tsui HY, Zhang J, Cheng F: Changes in the prevalence of HIV-related behaviors and perceptions among 1832 injecting drug users in Sichuan, China. Sex Transm Dis 2008, 35:325-335

76. Laufer FN: Cost-effectiveness of syringe exchange as an HIV prevention strategy. J Acquir Immune Defic Syndr 2001, 28:273-278.

77. McGrath JW, Celentano DD, Chard SE, Fullem A, Kamya M, Gangakhedar RR, Khamboonruang C, Joglekar N, Malhotra-Kohli R, Kiwanuka A, Sirirojn $B$ : A group-based intervention to increase condom use among HIV serodiscordant couples in India, Thailand, and Uganda. AIDS Care 2007, 19:418-424

78. Kamali A, Quigley M, Nakiyingi J, Kinsman J, Kengeya-Kayondo J, Gopal R, Ojwiya A, Hughes P, Carpenter LM, Whitworth J: Syndromic management of sexually-transmitted infections and behaviour change interventions on transmission of HIV-1 in rural Uganda: a community randomised trial. Lancet 2003, 361:645-652.

79. Siegfried N, Muller M, Volmink J, Deeks J, Egger M, Low N, Weiss H, Walker $\mathrm{S}$, Williamson P: Male circumcision for prevention of heterosexual acquisition of HIV in men. Cochrane Database Syst Rev 2003:CD003362.

80. Stoltz JA, Wood E, Small W, Li K, Tyndall M, Montaner J, Kerr T: Changes in injecting practices associated with the use of a medically supervised safer injection facility. J Public Health (Oxf) 2007, 29:35-39.

81. Thomsen SC, Ombidi W, Toroitich-Ruto C, Wong EL, Tucker HO, Homan R, Kingola N, Luchters S: A prospective study assessing the effects of introducing the female condom in a sex worker population in Mombasa, Kenya. Sex Transm Infect 2006, 82:397-402.

82. Vickerman P, Kumaranayake L, Balakireva O, Guinness L, Artyukh O, Semikop T, Yaremenko O, Watts C: The Cost-Effectiveness of Expanding Harm Reduction Activities for Injecting Drug Users in Odessa, Ukraine. SexTransm Dis 2006, 33:S89-102.

83. Wu Z, Luo W, Sullivan SG, Rou K, Lin P, Liu W, Ming Z: Evaluation of a needle social marketing strategy to control HIV among injecting drug users in China. Aids 2007, 21(Suppl 8):S115-122.

84. AuBuchon JP, Birkmeyer JD, Busch MP: Cost-effectiveness of expanded human immunodeficiency virus-testing protocols for donated blood. Transfusion 1997, 37:45-51.

85. Gowing L, Farrell M, Bornemann R, Ali R: Substitution treatment of injecting opioid users for prevention of HIV infection. Cochrane Database Syst Rev 2004:CD004145.

86. Gray RH, Li X, Kigozi G, Serwadda D, Nalugoda F, Watya S, Reynolds SJ, Wawer M: The impact of male circumcision on HIV incidence and cost per infection prevented: a stochastic simulation model from Rakai, Uganda. Aids 2007, 21:845-850. 
87. Kahn JG, Marseille E, Auvert B: Cost-Effectiveness of Male Circumcision for HIV Prevention in a South African Setting. PLoS Med 2006, 3:2349-2358.

88. Pang L, Hao Y, Mi G, Wang C, Luo W, Rou K, Li J, Wu Z: Effectiveness of first eight methadone maintenance treatment clinics in China. Aids 2007, 21(Suppl 8):S103-107.

89. Pronyk PM, Hargreaves JR, Kim JC, Morison LA, Phetla G, Watts C, Busza J, Porter JD: Effect of a structural intervention for the prevention of intimate-partner violence and HIV in rural South Africa: a cluster randomised trial. Lancet 2006, 368:1973-1983.

90. Pronyk PM, Kim JC, Abramsky T, Phetla G, Hargreaves JR, Morison LA, Watts C, Busza J, Porter JD: A combined microfinance and training intervention can reduce HIV risk behaviour in young female participants. Aids 2008, 22:1659-1665.

91. Roland ME, Neilands TB, Krone MR, Katz MH, Franses K, Grant RM, Busch MP, Hecht FM, Shacklett BL, Kahn JO, et al:: Seroconversion following nonoccupational postexposure prophylaxis against HIV. Clin Infect Dis 2005, 41:1507-1513.

92. Wawer MJ, Sewankambo NK, Serwadda D, Quinn TC, Paxton LA, Kiwanuka N, Wabwire-Mangen F, Li C, Lutalo T, Nalugoda F, et al.: Control of sexually transmitted diseases for AIDS prevention in Uganda: a randomised community trial. Rakai Project Study Group. Lancet 1999, 353:525-535

93. Weiss HA: Male circumcision as a preventive measure against HIV and other sexually transmitted diseases. Curr Opin Infect Dis 2007, 20:66-72.

94. Weiss HA, Quigley MA, Hayes RJ: Male circumcision and risk of HIV infection in sub-Saharan Africa: a systematic review and meta-analysis. Aids 2000, 14:2361-2370

95. Wilkinson D, Ramjee G, Tholandi M, Rutherford G: Nonoxynol-9 for preventing vaginal acquisition of HIV infection by women from men. Cochrane Database Syst Rev 2002:CD003936.

96. Wong KH, Lee SS, Lim WL, Low HK: Adherence to methadone is associated with a lower level of HIV-related risk behaviors in drug users. J Subst Abuse Treat 2003, 24:233-239.

97. Young TN, Arens FJ, Kennedy GE, Laurie JW, Rutherford G: Antiretroviral post-exposure prophylaxis (PEP) for occupational HIV exposure. Cochrane Database Syst Rev 2007:CD002835.

98. Bertrand JT, O'Reilly K, Denison J, Anhang R, Sweat M: Systematic review of the effectiveness of mass communication programs to change HIV/ AIDS-related behaviors in developing countries. Health Educ Res 2006, 21:567-597.

99. Ono S, Kurotaki T, Nakasone T, Honda M, Boon-Long J, Sawanpanyalert P, Kimura K: Cost-Effectiveness Analysis of Antiretroviral Drug Treatment and HIV-1 Vaccination in Thailand. Jpn J Infect Dis 2006, 59:168-173.

100. Gregson S, Adamson S, Papaya S, Mundondo J, Nyamukapa CA, Mason PR, Garnett GP, Chandiwana SK, Foster G, Anderson RM: Impact and process evaluation of integrated community and clinic-based HIV-1 control: a cluster-randomised trial in eastern Zimbabwe. PLoS Med 2007, 4:e102.

\section{Pre-publication history}

The pre-publication history for this paper can be accessed here: http://www.biomedcentral.com/1471-2458/10/401/prepub

\section{doi: $10.1186 / 1471-2458-10-401$}

Cite this article as: Pattanaphesaj and Teerawattananon, Reviewing the evidence on effectiveness and cost-effectiveness of HIV prevention strategies in Thailand BMC Public Health 2010, 10:401

\section{Submit your next manuscript to BioMed Central} and take full advantage of:

- Convenient online submission

- Thorough peer review

- No space constraints or color figure charges

- Immediate publication on acceptance

- Inclusion in PubMed, CAS, Scopus and Google Scholar

- Research which is freely available for redistribution

Submit your manuscript at www.biomedcentral.com/submit
C) Biomed Central 